\title{
Geochemical characterization of the mining district of Linares (Jaen, Spain) by means of XRF and ICP-AES
}

\author{
L. Arenas, M. Ortega, M.J. García-Martínez , E. Querol, J.F. Llamas \\ Departanento de ingeniería Quínica y Combustibles, E.T.S.I. de Minas de Madrid, Universidad Politécrica de Madrid, C/ Alenza, 4. 4" planta. 28003, Madrid, Spain
}

\begin{abstract}
A B S T R A C T
Linares (Jaen, Spain) has been subjected to an intense mining and metallurgic activity during 2500 years. Basically, lead and silver have been extracted from galena; as well as copper and zinc. Diferent studies have been conducted to evaluate trace element concentrations to obtain relationships with anthropogenic and geologic factors. The analytical results of these studies have been obtained with ICP-AES. This analytical technique is relatively expensive and inaccessible in zones with scarce economic means. In this study, XRF analyses have been conducted and the obtained results are presented, as well as a comparison with the previously obtained ICP results. In both cases, a cluster analysis has been made to try to identify the same relations in the target area. 5 groups have been identified, mainly related with lithology. Only 10 of the 122 grid squares (each one of $1 \mathrm{~km}^{2}$ ) are classified in different groups if the cluster analysis is conducted with XRF results or ICP results. ICP classifies better where these grid squares are located, mostly, in contact zones of different lithologies.
\end{abstract}

\section{Introduction}

The place of study is located in the mining district of Linares. It covers a surface of $126 \mathrm{~km}^{2}$ that has been divided in 126 squared patterns, each one with an area of $1 \mathbf{~ k m}^{2}$. The mining district is located on a substratum in which several geological units can be distinguished, mainly by granites and phyllites of the Paleozoic, sandstones and lutites of the Trias and marls of the Miocene (Martinez et al., 2007) (Fig. 1).

The wide and intense mining, mineralurgical (gravimetry and flotation) and metallurgical activities developed in the mining zone of Linares (south of Spain) have generated collections of sterile of mine in dumps of blocks, rafts of washer thins, collections of washer thicks and collections of slags. Both the mining activities and the geological natural conditions make predictable that the concentrations of some elements in the soil overcome the normal ranges in undisturbed areas. The area has been characterized historically due to the exploitation of veins of galena (PbS), though the paragenesis also includes other minerals as sphalerite ( $\mathrm{ZnS})$, chalcopyrite $\left(\mathrm{CuFeS}_{2}\right)$, and baryte (BaSO ${ }_{4}$ ) (Azcárate and Argüelles, 1971; Azcárate, 1977; Fontboté, 1982; Lillo, 1992, 2003).

It exiscs, therefore, a real need to evaluate the levels of concentration of the trace elements in the soils of the region of Linares. In the year 2002 , a doctoral thesis on environmental geochemistry was defended in
Linares (Martínez, 2002). In this work, ICP-AES analytical technology was used for the characterization of the samples. This analytical technology is not always available, especially in developing countries. For that reason, the analysis of this study has been carried out by means of another more accessible and economic analytical technology. This technology is the X-ray fluorescence (XRF) analysis whose needs are much more attainable both for laboratory equipment and sample preparation. It is difficult and time consuming to undertake a tocal elemencal analysis following the ICP-AES method because the sample must usually be dissolved. It is well known that sometimes it is difficult to dissolve sediments and soils, as some parts may be filtered out during the sample preparation procedure. Clearly, in the sample treatment, loss of some elemencs or sample concamination may occur. X-ray fluorescence analysis is a non-destructive method, possessing the advantage that the total elemental content of the samples can be obtained without any complicated sample pre-treatment (Somogyi et al., 1997). ICP-AES has high initial and maintenance costs and it uses high intakes of $\mathrm{Ar}$ and electriciry. Nowadays, this technique is being competitive with XRF due to economy of scale in some laboratories Another advancage of XRF is that it can be used on site to identify major and minor elements.

The comparison of the results obtained using both analytical technologies allows to obcain the results with its "background" associated values, the definition of anomalous concentrations inside the characteristics of the emplacement that is being studied, as well as the identification of the contributions of trace elements from different sources (natives, anthropics, agriculturalists ...). The spatial study of the values distribution has been carried out with 


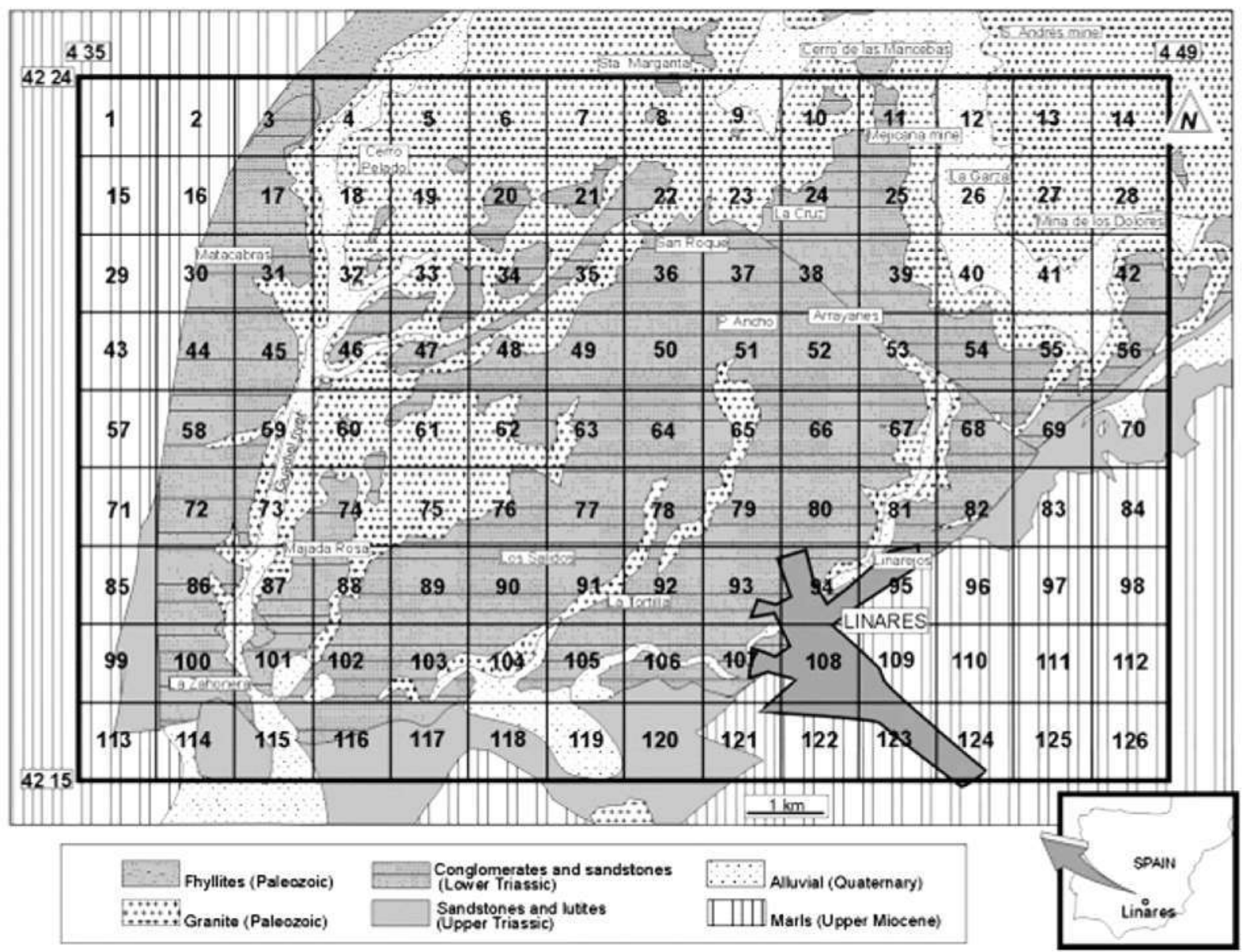

Fig. 1. Main lithologies in the area, principal mining district zones (mines, foundries, and industrial parks) and grid square distribution (J. Martínez et al., 2007).

the help of different statistical multivariant techniques and of geostatistical tools.

It is of interest the development of methodologies for geochemical characterization, using different analytical technologies, with a general application, not only restricted to the district of Linares, giving response to a new approach of increasing development in the study and resolution of environmental problems.

\section{Methods and materials}

\subsection{Sample collection}

The samples were collected for the accomplishment of a doctoral thesis (Martinez, 2002) carried out during a previous pilot study that indicated the need to gather five increases of $1500 \mathrm{~g}$ each from every squared pattern soil by means of an Auger sampler. These already collected and analyzed samples were used for this study.

\subsection{Sample preparation and analysis}

The sample preparation for the analysis by means of XRF was carried out in the Centralized laboratory of the Madrid School of Mining Engineers using pressed tablets. In this technique, 6-8 $\mathrm{g}$ of sample is compressed under a pressure of $2-3 \mathrm{t} / \mathrm{cm}^{2}$, to give a tablet of $31.5 \mathrm{~mm}$ of diameter and $4-5 \mathrm{~mm}$ of thickness. A binder is almost always used to avoid crumbling. In the present study, to carry out the above mentioned preparation of the pressed tablet, $8 \mathrm{~g}$ of the sample is mixed with $3.5 \mathrm{~cm}^{3}$ of elvacite (binder) solution. This mixture was inserted in a press (Research \& Industrial Instruments Company, 30 ton press (-30) to obtain a tablet that, later on, was introduced in the analysis equipment (Philips, PW 1404, XRF Spectrometer). The anode of the tube of X-rays is made of Sc-Mo, so the results for these two elements have not been taken into account.

The analysis of the samples by means of ICP-AES was conducted in ACME laboratories (ACME Analytical Laboratories Ltd.) in Vancouver (Canada). The sample preparation was carried out with a total acid attack. One gram of the fraction smaller than $63 \mu \mathrm{m}$ is attacked chemically with $\mathrm{HNO}_{3}, \mathrm{HClO}_{4}, \mathrm{HF}$ and $\mathrm{HCl}$ in an open Teflon reactor. Every sample in dissolution was analyzed with ICP-AES.

\section{Analysis of results}

Table 1 summarises the results for the elements analyzed: mean, median, standard deviation, minimum, and maximum values for the original data are given.

Before carrying out the cluster analysis, a study of the "enrichment factor" (E.F.) of the different elements analyzed in the zone of study was conducted. The enrichment factor is the factor by which it is necessary to multiply the normal abundance of an element (the Clarke) in the terrestrial crust to obtain an economically exploitable concentration. For example, the normal abundance of lead in the terrestrial crust is $0.0001 \%$ and its enrichment factor is 2000 . So a lead deposit should contain $0.2 \%$ of lead. However, the feasibility of exploiting a deposit depends on many other factors such as geology of the sector, product pricing, cost of purification, geography, climate, infrastructure, national politics, political trust, socio-economic stability, interest rate, industrial growth and so on.

The study of the enrichment factor started with the mean of every element in the zone of study and the calculation of the enrichment factor afterwards, the latter determined as the relation between a) the 
Table 1

Statistical data: mean, minimum, maximum, median, and standald deviation, Values of concentration are expressed in $1 \mathrm{ng} \mathrm{kg}^{-1}$.

\begin{tabular}{|c|c|c|c|c|c|c|c|c|c|c|c|}
\hline & Mean & Min & $\operatorname{Max}$ & Median & Standard deviation & & Mean & Min & $\operatorname{Max}$ & Median & Standard deviation \\
\hline Mo.icp & 1.88 & 1.50 & 15.00 & 1.50 & 1.52 & Ca.icp & 34636.07 & 1700.00 & 207600.00 & 13300.00 & 43599.36 \\
\hline Mo.xr厂 & 56.14 & 35.00 & 94.00 & 53.00 & 13.76 & Caxr & 37745.49 & 2970.00 & 211200.00 & 15250.00 & 45502.04 \\
\hline Cuicp & 141.17 & 14.00 & 1654.00 & 53.50 & 233.60 & P.icp & 867.05 & 330.00 & 2920.00 & 780.00 & 444.95 \\
\hline Cu.xr & 812.73 & 400.00 & 2100.00 & 660.00 & 492.97 & P.xIf & 798.00 & 541.00 & 1340.00 & 771.00 & 235.01 \\
\hline Pb.icp & 4148.98 & 25.00 & 38419.00 & 1346.50 & 7134.92 & La.icp & 68.94 & 17,00 & 145.00 & 69.50 & 22.89 \\
\hline Pbxif & 4352.47 & 36.00 & 62600.00 & 1315.00 & 8424.30 & cricp & 50.02 & 28.00 & 150.00 & 49.00 & 15.43 \\
\hline Zn.icp & 110.43 & 27,00 & 953.00 & 74.00 & 121.75 & cl:xif & 300.00 & 300.00 & 300.00 & 300.00 & $N A$ \\
\hline Zn.xrf & 139.79 & 26.00 & 880.00 & 104.00 & 137.62 & Mg.icp & 6179.51 & 2500.00 & 12300.00 & 5900.00 & 2336.66 \\
\hline Ag.icp & 2.09 & 0.50 & 29.00 & 0.50 & 3.88 & Mg.xr & 9305.41 & 4800.00 & 17500.00 & 9055.00 & 2795.37 \\
\hline Ag $\times \Gamma^{-}$ & 24.00 & 20.00 & 30.00 & 23.00 & 4.32 & Ba.icp & 862.92 & 120.00 & 3464.00 & 703.50 & 655.50 \\
\hline Ni.icp & 20.43 & 10.00 & 40.00 & 20.00 & 5.83 & Ba.xr & 1249.30 & 241.00 & 11400.00 & 770.00 & 1525.80 \\
\hline Co.icp & 12.27 & 5.00 & 39.00 & 10.00 & 6.15 & Ti.icp & 3320.49 & 1500.00 & 6400.00 & 3000.00 & 1083.07 \\
\hline co.xlf & 41.92 & 20.00 & 69.00 & 41.00 & 11.48 & Ti.xlf & 5979.51 & 2660.00 & 9510.00 & 5990.00 & 1419.27 \\
\hline Mn.icp & 1236.05 & 194.00 & 3981.00 & 1094.50 & 813.41 & Alicp & 63549.18 & 30100.00 & 114200.00 & 57350.00 & 19989.32 \\
\hline Mn.xn & 1420.09 & 390.00 & 3930.00 & 1350.00 & 758.37 & Al.xif & 83959.02 & 41300.00 & 119100.00 & 82200.00 & 16978.73 \\
\hline Fe.icp & 32254.92 & 15900.00 & 60500.00 & 31050.00 & 8873.06 & Na.icp & 4902.46 & 1500.00 & 16400.00 & 3300.00 & 3624.90 \\
\hline Fe.xr & 36656.56 & 18300.00 & 65500.00 & 35100.00 & 10404.70 & Na.xif & 3710.16 & 660.00 & 13400.00 & 2470.00 & 2797.99 \\
\hline As.icp & 25.33 & 3.00 & 162.00 & 17.00 & 26.31 & Kicp & 25508.20 & 10100.00 & 38300.00 & 24800.00 & 6828.17 \\
\hline As.xrf & 77.50 & 56.00 & 100.00 & 75.00 & 17.56 & K.xlf & 29540.98 & 10800.00 & 45900.00 & 28850.00 & 8018.01 \\
\hline U.xr & 20.00 & 20.00 & 20.00 & 20.00 & $\mathrm{NA}$ & W.icp & 5.99 & 2.50 & 70.00 & 5.00 & 7.94 \\
\hline Tlı.icp & 26.16 & 4.00 & 80.00 & 21.00 & 15.51 & Zr.icp & 104.20 & 36.00 & 238.00 & 100.00 & 33.45 \\
\hline Thexf & 134.50 & 128.00 & 141.00 & 134.50 & 9.19 & Zr.xr & 786.05 & 141.00 & 1760.00 & 793.00 & 293.44 \\
\hline Sricp & 149.25 & 60.00 & 523.00 & 121.50 & 88.72 & Sn.icp & 5.65 & 1.50 & 51.00 & 4.00 & 5.96 \\
\hline Sr.xrf & 163.43 & 79.00 & 490.00 & 140.00 & 84.17 & Sn.xr & 60.50 & 34.00 & 87.00 & 60.50 & 37.48 \\
\hline Cd.icp & 0.77 & 0.50 & 5.00 & 0.50 & 0.63 & Y.icp & 22.36 & 9.00 & 48.00 & 19.50 & 8.96 \\
\hline Sb.icp & 11.14 & 3.00 & 186.00 & 3.00 & 21.50 & YxIf & 65.65 & 30.00 & 119.00 & 62.50 & 21.09 \\
\hline Sb.xrf & 70.25 & 35.00 & 179.00 & 52.50 & 46.30 & Nb.icp & 9.82 & 5.00 & 24.00 & 8.00 & 4.54 \\
\hline Bi.icp & 3.18 & 3.00 & 9.00 & 3.00 & 0.92 & Nbxif & 50.00 & 50.00 & 50.00 & 50.00 & 0.00 \\
\hline Vicp & 72.48 & 43.00 & 124.00 & 72.50 & 13.36 & Be.icp & 3.76 & 1.00 & 6.00 & 4.00 & 1.43 \\
\hline V.xr & 93.05 & 52.00 & 175.00 & 91.50 & 19.34 & Sc.icp & 11.80 & 6.00 & 25.00 & 10.00 & 4.16 \\
\hline
\end{tabular}

concentration of the element with regard to the Ytrium concentration in the zone of study and b) the relation of the Clarke of the element with regard to the Ytrium in acid rocks:

$$
E . F .=\frac{\frac{[\text { Element concentration] }}{\text { Yernum concentration] }}}{\frac{\text { [Clarke of the element in acid rocks }]}{\text { [Clarke of Ytrium in acid rocks] }}} \text {. }
$$

The values escablished by Mason and Moore (1982) were used as the Clarke for every element in the acid rocks. Lawson and Winchester (1979) escablished a scale to determine the origin of the element that is studied. The above mentioned authors indicated that an enrichment factor above 500 indicates serious pollution of anthropic origin, whereas if it is minor to 10 , it indicates that the above mentioned element comes from the rock (natural origin).

The elements shown to be more enriched in the emplacement were, in this order:

a) According to ICP results: $\mathrm{Pb}$ (1856 times more), $\mathrm{Sb}$ (55 times more), Ag (23 times more), As (15 times more), and Cd (10 times more) and also a slight enrichment is observed in $\mathrm{Cu}(4.2$ times more) and Mo (2.06 times more).

b) According to XRF results: Pb (663 times more), Sb (54 times more), Ag (49 times more), and As (16 times more) and also a slight enrichment is observed in Cu ( 8.3 times more). By means of XRF, Cd has not been detected and Mo result is invalidated because the anode of the XRF tube was made from Mo.

The first thing remarkable is the disparicy between XRF and ICP$A E S$ values. Whereas for $S b$ and As the enrichment values of both technologies are similar, for Pb there is three times more enrichment by means of ICP, and for $\mathrm{Ag}$ and $\mathrm{Cu}$ there is twice more enrichment by means of XRF.

As it can be observed in Fig. 2, all the analyzed elements with anomalies have a greater upper limit of detection by means of XRF than by means of ICP-AES (except for Pb). Therefore the mean is always higher for XRF than for ICP. The fact that ICP gives, sometimes, a higher enrichment factor than XRF is not related with greater concentrations of the element but with the fact that concentration of Ytrium by means of ICP is $22 \mathrm{ppm}$ whereas by means of XRF is $66 \mathrm{ppm}$ ( 3 times more). The only exception is $\mathrm{Pb}$ (in which almost all the results obtained by means of XRF are over the limit of detection of the technique, probably due to the high occurrence in the zone) and it is the only case in which XRF's average ( $4352 \mathrm{ppm}$ ) and ICP's average (4149 ppm) are very similar.

The results obcained suggest that a more detailed comparison study of both techniques for the elements enriched in the zone of study is advisable:

- $\mathrm{Pb}, \mathrm{Cu}$, and $\mathrm{Sb}$. For these elements, a good correlation exists between the results obtained with both techniques. In such graphs the values are very close to the line in which, theoretically, all the represented points should be: a line starting at 0 with a slope of 1 . Ideally, the results obtained for each cell by means of XRF should overlap the results obtained by means of ICP-AES for each sample. For $C u$ and $S b$, there are some " $y$ " values with $x=0$; this behaviour owes to the fact that small concentrations are being detected with ICP-AES (more sensitive technique) which cannot be detected with XRF because they are below the detection limit of the equipment.

- Ag, As, and $\mathrm{Y}$. The dispersion graphs show a widespread trend of points concentrated parallel to the " $y$ " axis and another numerous concentration in the right side of the graphs, close to the " $x$ " axis (high XRFs concentrations with low ICP-AES's concentrations). These graphs indicate either a weakly positive correlation or no correlation at all. These graphs show two differentiated trends:

- Some of them show that, certain elements, in most of the samples, only are detected by means of ICP-AES but not by means of XRF; they are those elements ( $A g$ and $A s$ ) in which almost all the points are parallel to the " $y$ " axis with " $x=0$ ". 

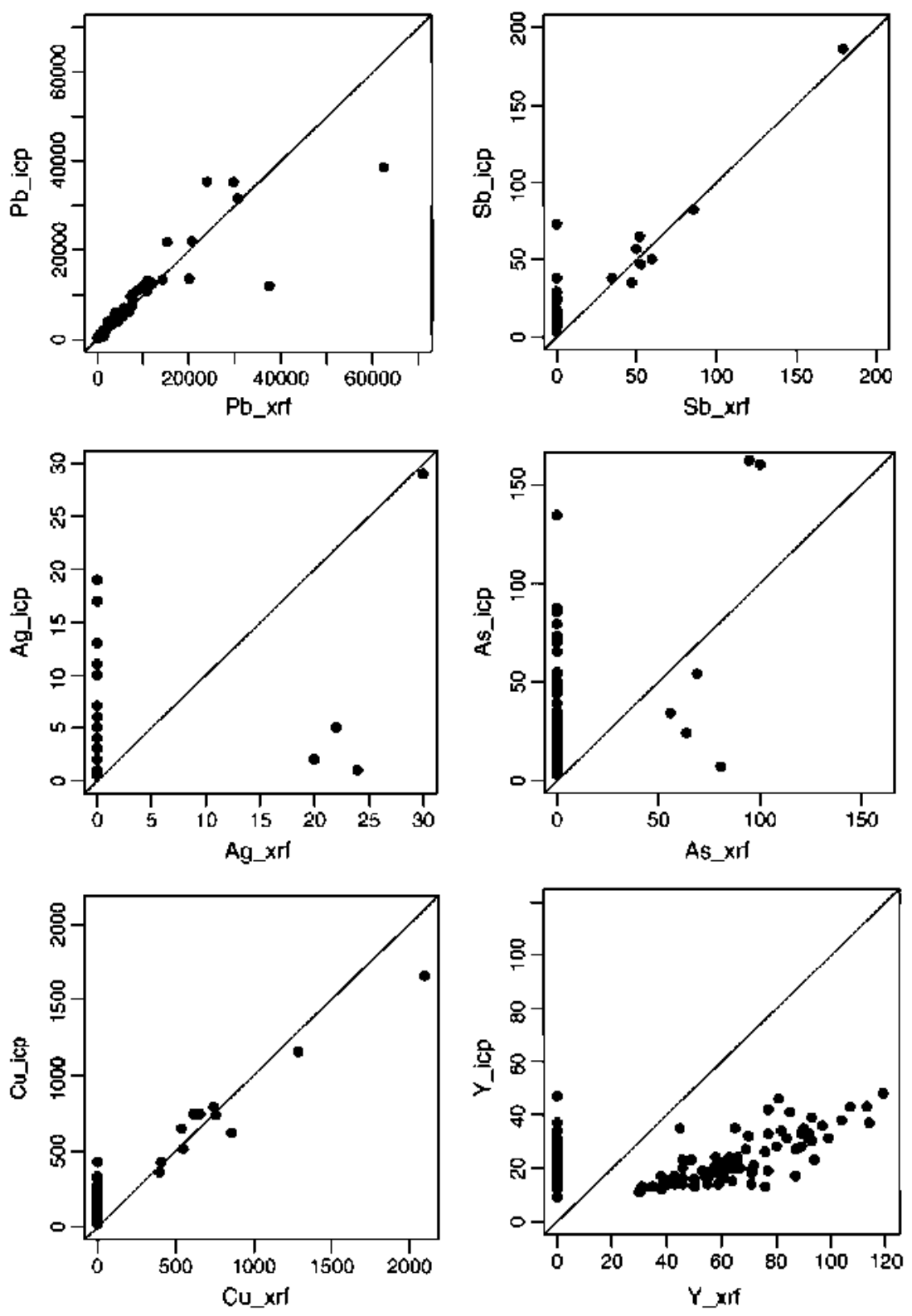

Fig 2. Graplis showing the correlation berween XRF and ICP-AES for the elements enriched in the zone: $\mathrm{Pb}$, Sb, Ag, As, Cu, and Mo. Y has also been included.

- For Y, the behaviour is more chaotic because, for the same ICPAES value, according to the different samples, sometimes the element is detected by means of XRF but by others it is not; and. in general, the concentrations obtained by means of XRF are quite higher than the concentrations obtained by means of ICPAES.

\section{Multivariate methods}

In spite of the discrepancies found between both techniques, in which is observed that the enrichment factors are usually higher for XRF than for ICP, an analysis of conglomerates (using fuzzy K-means conglomeration method and the Square Euclidean distance) was performed to show if the separation in natural groups matches both techniques. Fuzzy $\mathrm{K}$-means was chosen because it has become the most well-known and powerful method in cluster analysis (Kuo-Lung and Yang, 2002).
The cluster analysis of the results obtained of the samples analyzed by means of XRF and by means of ICP-AES can be observed in Figs. 3 and 4 . The variables that have been in use are the results obtained in the analyses (in ppm). In case of XRF, the Ni, La, and Be results are rejected because there are no valid cases and the statistics cannot be calculated. Sc and Mo have also been eliminated because the anode of the XRF tube was made from these elements. In case of ICP-AES, $U$ and $A u$ are eliminated because there are no valid cases. The multivariate analysis carried out with ICP-AES's results has already been conducted, though using the logarithms of the results instead (Martínez López et al., 2008).

The white squared patterns were excluded from the analysis provided that they correspond to pilot squared pacterns $(38,58$, and 110) that were sampled according to a different methodology (Martinez, 2002). It was decided to exclude them from the analysis to avoid interference in the results produced by a different sampling technique. Squared partern 112 was also excluded from the analysis because its results were outliers due to some problems in the analysis by XRF. 




Fig. 3. Squared patterns coloured according to the five different groups obtained as a result of the clustering analysis (method Ward, squared Euclidean distance) of the concentrations of the elements analyzed by XRF. The number on the top of each cell stands for the number of the squared pattern and the number below stands for the cluster's number.

Five different groups can be observed in Figs. 3 and 4:

1. Cluster 1 cells correspond to granite outcrops. The activity that prevails is mining and, in a minor way, mineralurgy, oak groves, and crops.

2. Cluster 5 cells are placed mainly on the Miocene. The principal activity is the culture of olive groves, grain farming and the urban one (given its proximity to Linares).

3. Cluster 3 cells are placed principally on Triassic areas, zones that have been affected by mining industry, metallurgy, mineralurgy, crops and in a minor way by olive groves.

4. Cluster 4 cells are placed mainly in zones of contact of Granite with Trias; in squared patterns where mining activity and crops have been carried out and, in minor way, mineralurgical and urban activities.

5. Cluster 2 cells are located principally on zones of Trias-Miocene's contact or in zones highly impacted, where mining or metallurgical activities have been located. In these squared patterns crops and mining were the main activities; emphasizing some cells where mineralurgy and metallurgy and also some urban activity have been carried out (squared patterns $25,51,53,63$, and 91).

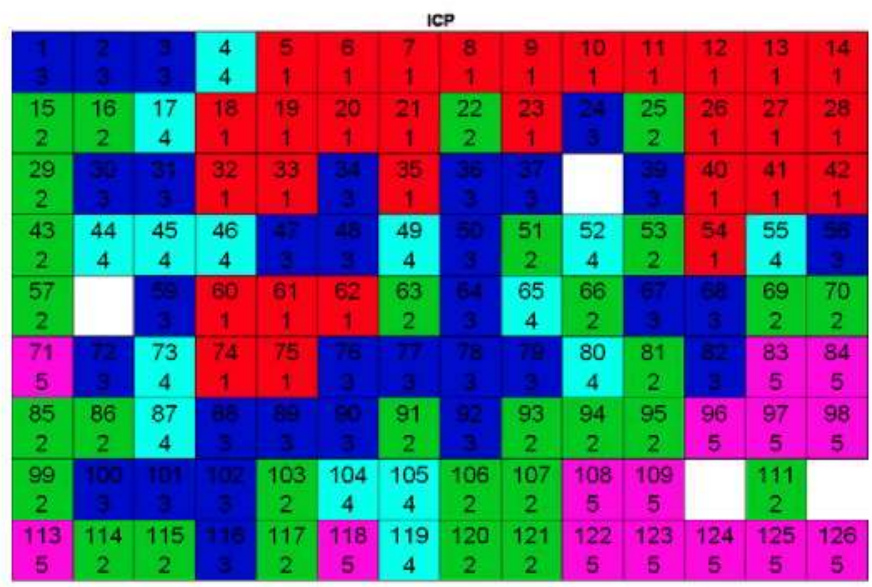

Fig. 4. Squared patterns coloured according to the five different groups obtained as a result of the clustering analysis (method Ward, squared Euclidean distance) of the concentrations of the elements analyzed by ICP. The number on the top of each cell stands for the number of the squared pattern and the number below stands for the cluster's number.
The first thing that is remarkable in Figs. 3 and 4 is that the clustering analysis has given very similar results independently of the analytical technique; which indicates that, though XRF should be a technology with worse detection limits, it is robust enough and these results are comparable to the results obtained by means of ICP-AES. Of the 122 squared patterns studied, only 10 of them $(8 \%)$ are grouped differently depending on the analytic technique. Subsequently a more detailed analysis of these 10 squared patterns was done, showing that these cells are located in zones of contact or of strong anthropic activity. It is important to remember at this point that in XRF the matrix effect influences greatly the results, therefore it is expected that the XRF results are greatly influenced by the lithology whereas ICP-AES's results, being independent from the matrix of the sample, are more independent from the above mentioned matrix effect.

$>$ Squared pattern 3. According to the lithology map, this cell is in a zone of Trias-Miocene contact. In Trias, there are no shales, common in the rest of Trias, but an alluvium appears. ICP groups this cell with Trias whereas XRF groups it with granite. Though the cell is close to the granitic zone, the alluvium of the Trias and the Miocene clearly predominates, for what it seems to be better grouped according to ICP's results. As for the anthropic activity, though there are oak groves, it is necessary to emphasize that it is in the proximities of "Cerro Pelado" which would indicate a strong mining activity. It is possible that the cell has residues proceeding from this near hill, which would indicate a strong influence of the mineralization (especially high concentrations in aluminium) that might be the cause why XRF groups it with granite (zone with mineralization).

$>$ Squared pattern 4. According to the lithology map, this cell is located in a zone of contact of quaternary granite with outcrop of the typical mineralization of the zone. Alluvium- $Q$ of Trias appears in minor proportion. According to XRF this cell would be on granite (high concentrations in $\mathrm{Fe}, \mathrm{Co}$, and $\mathrm{Ti}$ in comparison with ICP; it also presents high concentrations of $\mathrm{Nb}$ in comparison with the rest of the cells, where it has not been detected by means of XRF) whereas according to ICP-AES it would be located in zones of contact between granite and Trias. It is also in the proximities of a hill where a strong mining activity is expected. It is, therefore, better classified by ICP.

$>$ Squared pattern 17. It is located in a zone of contact between alluvium- $Q$ and shales of Trias and granite with mineralization of Quaternary. According to XRF the cell would be grouped by those of Trias. According to ICP it would remain classified as a zone of contact Trias-granite. ICP classifies better the cell, although the fact that XRF classifies it as Trias (low concentration in zirconium in comparison with ICP) seems to indicate that the anthropic activity related to the mineralization typical of the zone does not seem to have a very strong influence in this cell, though it is located very close to the hill with the above mentioned mineralization outcrop.

$>$ Squared patterns 45 and 46. Zone of contact of Trias with Granite. According to XRF they would remain classified as granite (the cell 45 with major concentrations in $\mathrm{Y}, \mathrm{Zr}$, and Ti in comparison with ICP and the cell 46 with major content in $\mathrm{Co}, \mathrm{V}, \mathrm{Ti}, \mathrm{Zr}, \mathrm{Mn}, \mathrm{Al}$ and $\mathrm{Y}$ ). According to ICP, it would remain classified under a zone of contact Trias-granite. ICP seems to classify better the cell but, given the obtained results by means of XRF, the cells seem to have a strong anthropic activity. In these squared patterns there are mining traces.

$>$ Squared pattern 55. In this squared pattern Trias, granite and mineralization of the zone could be identified. According to XRF it would be in Trias (minor concentration of $\mathrm{Fe}, \mathrm{K}, \mathrm{Na}, \mathrm{Mn}$ and $\mathrm{Ba}$ than ICP). According to ICP it would be in a zone of contact Triasgranite. Therefore, it might say that the cell would be better classified by means of ICP. XRF seems to indicate the absence of a strong anthropic activity related to the mining activity of the zone. 
$>$ Squared pattern 72 . Zone of concact of Trias with granite and the mineralization of the zone. According to XRF, it would be in a zone of contact of Trias and Miocene (major concentrations of Al, Ti, V, $\mathrm{Ca}, \mathrm{Mg}, \mathrm{As}, \mathrm{Fe}$, and $\mathrm{K}$ than ICP). According to ICP, it would be in Trias. Though none of the two classifications is completely correct, it seems that it remains better classified according to ICP. XRF's results seem to indicate the absence of a strong anthropic activity.

$>$ Squared patterns 73 and 87. They are located in zones of contact of Trias with granite. According to XRF, they would be in granite (the cell 73 with major concentrations in $\mathrm{Co}, \mathrm{Al}$ and $\mathrm{Ti}$ in comparison with ICP and the cell 87 with major contents in Y, Sr, Co and Ti). According to ICP it would be located in zones of concact Triasgranite. ICP better classifies the cells, though in the cell 73 predominates the granite.

$>$ Squared pattern 103. It is located in Trias. According to XRF it would remain classified under a zone of concact Trias-granite (major concentrations of $\mathrm{Al}, \mathrm{Zr}$ and Ti than ICP). According to ICPAES it would be classified under a Trias-Miocene contact zone. None of these two classifications are correct, though XRF approaches more to the proximities of the cell. It would possibly be an anthropic activicy that impedes the correct classification of this zone in Miocene. This cell is close to the former mine of "Los Salidos" and mining traces have been identified.

\section{Conclusions}

In a study where the cells in which the classifications of the results obtained by means of ICP and XRF are different, it is observed that the principal differences are in zones of contact between two lithologies ( 9 of 10 differently grouped cells). Therefore, these differences are independent to a great extent from the pollution of the zone. ICP is capable of differentiating better these zones of contact. XRF (probably due to the matrix effect) usually has problems at the moment of identifying these zones of contact and, sometimes, it selects one of the two lithologies depending on which matrix dominates in the collected sample. It is also necessary to keep in mind that ICP is capable of detecting more elements (lower detection limits), which helps at the moment of classifying better the cells. Though ICP is more precise at the moment of identifying zones of mixing lithologies, this technique is more expensive both in the preparation and in the analysis of the samples. Therefore, it is possible to conclude that both technologies allow a good identification of the different lithologies present in mining districts.

\section{References}

Azcárate, J.E., 1977. Ceological map and explanatory memorandum of the 905 sheet (Linares), 1:50.000. Geological and Mining Institute of Spain.

Azcarate, J.E., Argüelles, A, 1971. Tectonic evolution and vein structures in the mining district of Linares. Congress Spanish-Portuguese-American of Econolnic Geology. Madrid, Volume I, Section 4, pp. .17-32.

Fontboté, J.M., 1982. Geological map and explanatory memorandum of the 70 sheet (Linares), scale 1:200, 000. Geological and Mining Institute of Spain.

Kuo-Lung, Wu. Yang. Miin-Shen, 2002. Alternative t-means clustering algorithms. Pattem Recognit, 35, 2267-2278.

Lawson, D.R., Winchester, J.W., 1979. A standand crustal aerosol as a reference for elemental enrichment factors. Atmos. Environ. 10, 925-930.

Lillo, J. 1992. Geology and geochemistry of Linares-La Carolina Pb-Ore field (Southeastem border of the Hesperial Massin). Ph D. Thesis, Univ. Leeds.

Lillo, J., 2003. Hydrothermal alteration in the Linares-La Carolina Ba-Pb-Zn-Cu- $(\mathrm{Ag})$ vein district, Spain: mineralogical data from El Coble vein. Trans. Inst. Min. Metal. Sect. B 111, B114-B118.

J. Martinez, 2002. Geochemical and emviromnental characterization of soils in the mining sector of Linares. Ph D. Thesis, Universidad Politécnica de Madrid, 2002.

Martínez López, J., Llamas Borrajo, J., de Miguel García, E., Rey Arrans, J., Estévez, Mㄴ.C. Sáez Castillo, A.J. 2008. Multivariate analysis of contanination in the mining district of Linares (Jaén, Spain). Appl. Geochem. 23, 2324-2336.

Martínez, J., Llamas, J., de Miguel, E., Rey, J., Hidalgo, M.C., 2007. Deternination of the geochemical background in a metal mining site: example of the mining district of Linares (South Spain). J. Geochem. Explor. 94, 19-29.

Mason, B., Moole, C.B., 1982. Principles of Geochemistry, 4th Edition. John Wiley \& Solns, New York $344 \mathrm{pp}$.

Somogyi, A., Braun, M., Posta, J., 1997. Comparison between X-ray fluorescence and inductively coupled plasma atomic emission spectrometry in the analysis of sediment samples. Spectrochim. Acta B 52, 2011-2017. 